CARDIOVASCULAR MEDICINE

\title{
Coronary calcifications in young patients with first, unheralded myocardial infarction: a risk factor matched analysis by electron beam tomography
}

\author{
K Pohle, D Ropers, R Mäffert, P Geitner, W Moshage, M Regenfus, M Kusus, \\ W G Daniel, S Achenbach
}

Heart 2003;89:625-628

See end of article for authors' affiliations

.....................

Correspondence to: Dr Karsten Pohle,

Ulmenweg 18, 91052

Erlangen, Germany;

karsten_pohle@yahoo.de

Accepted

9 January 2003

\begin{abstract}
Objective: To compare the presence and extent of coronary calcifications in young patients with first, unheralded acute myocardial infarction with matched controls without a history of coronary artery disease.

Methods: In 102 patients under 60 years of age (19-59 years, mean 41 years; 88\% male), electron beam tomography was done 1-14 days after acute myocardial infarction, before any coronary intervention. Coronary calcifications were quantified using the Agatston score. Age related calcium centiles were determined based on the Mayo Clinic "epidemiology of coronary calcification" study, and results were compared with a group of 102 controls without coronary artery disease, matched for sex, age, and risk factors.

Results: Calcifications were present in $95.1 \%$ of patients with acute myocardial infarction and in $59.1 \%$ of controls $(p=0.008)$. The mean (SD) Agatston score was 529 (901) in the infarct patients versus 119 (213) in the controls ( $p<0.001)$. An Agatston score above the 50th centile was present in $87.2 \%$ of infarct patients and $47.0 \%$ of controls $(p=0.006)$, and above the 90 th centile in $60.7 \%$ of infarct patients and only $5.8 \%$ of controls $(p=0.001)$.

Conclusions: In young patients with their first, unheralded acute myocardial infarction, the presence and extent of coronary calcium are significantly greater than in matched controls.
\end{abstract}

$E^{1}$ lectron beam tomography is a sensitive tool for detecting and quantifying coronary calcifications. ${ }^{1}$ The amount of coronary calcium correlates with the amount of coronary atherosclerotic plaque. ${ }^{2-5}$ Thus the presence and extent of coronary artery calcification has been shown to be associated with an individual's risk for cardiovascular events. ${ }^{6-12}$

In up to $50 \%$ of patients who suffer an acute myocardial infarct, this event is the first clinical manifestation of coronary artery disease. ${ }^{13}$ Recent studies have shown detectable coronary calcifications in $95 \%$ of patients with acute coronary syndromes..$^{14}$ However, in younger individuals, coronary events often occur in the presence of early stages of coronary artery disease, presumably caused by the rupture of lipid-rich coronary plaques, ${ }^{16-18}$ and coronary calcification may be less prevalent than in older patients with acute myocardial infarction. ${ }^{19}$ The value of electron beam tomography in detecting relatively young patients at risk of acute myocardial infarction is therefore less clear and has so far not been investigated.

Our aim in this study was to assess the prevalence and the extent of coronary calcification in younger patients with a first, unheralded acute myocardial infarct in comparison with matched controls without a history of coronary artery disease.

\section{METHODS}

\section{Patients and controls}

We recruited 102 patients under 60 years of age with an unheralded, first transmural myocardial infarct established by ST elevation on the ECG and increased serum markers of myocardial damage (creatine kinase, creatine kinase $\mathrm{MB}$ isoenzyme, and troponin C). Patients with a previously established diagnosis of coronary artery disease, atrial fibrillation, possible pregnancy, or renal failure were excluded from the investigation. In all individuals, electron beam tomography was undertaken before any coronary intervention and within 14 days of the myocardial infarct. In all patients, invasive coronary angiograms were obtained after the electron beam tomographic study. This enabled us to identify the culprit vessel.

Cardiovascular risk factors were identified by patient interviews and a review of the medical case notes. The following risk factors were assessed: current smoking; hypertension (on antihypertensive drugs, or with known and untreated hypertension); diabetes (the use of insulin or oral hypoglycaemic agents); a family history of coronary heart disease; and hypercholesterolaemia (the use of cholesterol lowering drugs, or a plasma low density lipoprotein cholesterol of $>4.14$ $\mathrm{mmol} / \mathrm{l}$ or total cholesterol of $>6.22 \mathrm{mmol} / \mathrm{l}$ ).

All patients gave their written informed consent to the investigation, and the study protocol was approved by the institutional ethics committee.

We obtained 102 controls without symptomatic coronary artery disease, matched for sex, age, and risk factors. Controls were recruited by reviewing electron beam tomographic studies that had been done on an outpatient basis in our centre between 1997 and 2001. Matching criteria were conformity in sex and in all risk factors; a difference of up to five years in age was allowed.

\section{Image acquisition and evaluation}

Imaging was done with an Imatron C-150 XP electron beam tomography scanner (Imatron Inc, South San Francisco, California, USA). Subjects were scanned in the supine position. After determination of the heart position, 40 axial cross

Abbreviations: $C X$, circumflex artery; $L A D$, left anterior descending coronary artery; RCA, right coronary artery 
Table 1 Characteristics of patients after acute myocardial infarction and controls

\begin{tabular}{|c|c|c|c|c|c|}
\hline \multirow[b]{3}{*}{ Characteristic } & \multicolumn{4}{|c|}{ Patients with AMI } & \multirow[b]{3}{*}{ Controls } \\
\hline & \multirow[b]{2}{*}{ Total } & \multicolumn{3}{|c|}{ Culprit vessel } & \\
\hline & & LAD & $c x$ & RCA & \\
\hline Number & 102 & 48 & 15 & 39 & 102 \\
\hline \multicolumn{6}{|l|}{ Age (years) } \\
\hline Mean (SD) & $41.2(7.0)$ & 41.9 (8.0) & $41.4(8.0)$ & $40.6(7.0)$ & 40.9 (9.0) \\
\hline Range & $19-59$ & $19-59$ & $22-59$ & $19-59$ & $22-59$ \\
\hline Sex (\% men) & 88.2 & 87.1 & 88.9 & 88.0 & 88.2 \\
\hline Hypercholesterolaemia (\%) & 88.2 & 89.1 & 82.6 & 94.0 & 87.1 \\
\hline Hypertension (\%) & 57.8 & 60.5 & 53.8 & 62.0 & 57.8 \\
\hline Family history of premature CAD (\%) & 48.0 & 51.0 & 44.2 & 50.0 & 48.0 \\
\hline Diabetes $(\%)$ & 16.6 & 19.2 & 16.2 & 14.0 & 16.6 \\
\hline Smoking (\%) & 67.6 & 68.9 & 71.2 & 64.0 & 67.6 \\
\hline
\end{tabular}

sections of the heart were acquired during inspiratory breath hold. Imaging was done using the high resolution single slice mode of the scanner with $100 \mathrm{~ms}$ exposure time, $3 \mathrm{~mm}$ slice thickness, and $3 \mathrm{~mm}$ table feed between consecutive slices. Image acquisition was triggered to the patient's ECG at $40 \%$ of the cardiac cycle. Cross sectional images were reconstructed with a $26 \mathrm{~cm}$ field of view using the scanner's "sharp" kernel.

Acquired images were transferred to an off-line workstation (NetraMD, ScImage, Los Altos, California, USA). Coronary calcifications were defined as areas of at least two contiguous pixels (area $>0.51 \mathrm{~mm}^{2}$ ) with a density of $130 \mathrm{HU}$ or more. Coronary calcifications were quantified using the Agatston score ${ }^{20}$ Age related calcium centiles were determined based on the epidemiology of coronary calcification study. ${ }^{21}$

\section{Statistical analysis}

Statistical analysis employed a PC based computer program (SPSS version 10.0). Comparisons between the score values of matched pairs were undertaken using the Student $t$ test for paired samples. Non-parametric analyses between the matched groups were done using the McNemar test. The distribution of patients and controls in age related calcium centiles was analysed using the $\chi^{2}$ test. Probability values of $p \leqslant 0.05$ were considered to indicate a significant difference.

\section{RESULTS}

\section{Patient characteristics}

Mean (SD) age was 41.2 (7) years in the infarction group and 40.9 (9) years in the control group (NS). Clinical characteristics of the two groups are shown in table l. Two of the 102 patients had no conventional risk factors, nine had one risk factor, 28 had two, 25 had three, and 38 had four or more. Electron beam tomography was done 8 (6) days (range 1-14 days) after the myocardial infarction.

\section{Detection of coronary calcification}

Coronary calcifications were present in 96 of the 102 patients with myocardial infarction and in 61 of the 102 controls (94.1\% $v 59.8 \%, p=0.008)$. In six of the 102 infarct patients, no coronary artery calcification was detected by electron beam tomography; invasive angiography revealed an absence of coronary stenoses in two of these cases, and single vessel coronary artery disease in the remaining four. The mean Agatston score of all 102 patients with myocardial infarction was 529 (903), while the mean score for the control group was 119 (213) $(\mathrm{p}=0.001)$.

Patients were separated by age into three subgroups (group $1,<35$ years; group 2, 35-44 years; group 3, 45-59 years). In group 1 (24 patients), the mean Agatston score in the infarct patients was $7.5(13.0) \vee 0.1(1.0)$ in the controls $(\mathrm{p}=0.007)$; in group 2 (42 patients), the values were 244.6 (401) $v 16.2$ (26) $(\mathrm{p}=0.01)$; and in group 3 (46 patients), they were 736.4 (1398) v $211.7(406)(\mathrm{p}=0.02)$.

An Agatston score above the 50th age related centile was present in $87.2 \%$ of the infarct group and in $47.0 \%$ of the control group $(p=0.006)$. A score above the 90th centile was found in $60.7 \%$ of the infarct group and in $5.8 \%$ of the control group $(p=0.001)$. Separating the subjects by age, in group 1 an Agatston score above the 90th centile was found in $89 \%$ of patients in the infarct group $v 4 \%$ in the control group $(\mathrm{p}<0.001)$; in group 2, in $74 \% v 12 \%(\mathrm{p}=0.02)$; and in group 3 , in $46 \%$ v $5 \%(\mathrm{p}=0.009)$.

\section{Calcification of the culprit vessel}

In 92 of the 102 patients with acute myocardial infarction $(90.2 \%)$, the culprit vessel was calcified (left anterior descending coronary artery (LAD), $87.5 \%(\mathrm{n}=48)$; circumflex artery $(\mathrm{CX}), 80.0 \%(\mathrm{n}=15)$; right coronary artery (RCA), $97.4 \%$ $(\mathrm{n}=39))$. In 10 patients, calcifications were only found in coronary arteries not related to the site of infarction. Of the

Table 2 Number of patients with myocardial infarction and controls with calcifications in the coronary vessels; patients with myocardial infarction are separated according to the culprit vessel

\begin{tabular}{|c|c|c|c|c|c|c|c|}
\hline & \multirow{2}{*}{$\begin{array}{l}\text { Culprit } \\
\text { vessel }\end{array}$} & \multicolumn{3}{|c|}{ Calcification present in: } & \multirow[b]{2}{*}{$c x$} & \multirow[b]{2}{*}{ RCA } & \multirow[b]{2}{*}{ Total } \\
\hline & & Number & LM & LAD & & & \\
\hline \multirow{4}{*}{$\begin{array}{l}\text { Palients after } \\
\text { AMl }\end{array}$} & LAD & 48 & $16 / 48(33 \%)$ & $42 / 48(88 \%)$ & $34 / 48(71 \%)$ & $32 / 48(67 \%)$ & $45 / 48(94 \%)$ \\
\hline & $C x$ & 15 & $6 / 15(40 \%)$ & $12 / 15(80 \%)$ & $12 / 15(80 \%)$ & $11 / 15(73 \%)$ & $14 / 15(93 \%)$ \\
\hline & RCA & 39 & $13 / 39(33 \%)$ & $37 / 39(95 \%)$ & $32 / 39(82 \%)$ & $38 / 39(97 \%)$ & $37 / 39(95 \%)$ \\
\hline & Total & 102 & $35 / 102(34 \%)$ & $91 / 102(90 \%)$ & $78 / 102(76 \%)$ & $81 / 102(79 \%)$ & $96 / 102(94 \%)$ \\
\hline Controls & & 102 & $11 / 102(11 \%)$ & $52 / 102(51 \%)$ & $40 / 102(39 \%)$ & $38 / 102(37 \%)$ & $61 / 102(60 \%)$ \\
\hline
\end{tabular}

$A M I$, acute myocardial infarction; $C X$, circumflex coronary artery; LAD, left anterior descending coronary artery; LM, left main coronary artery; RCA, right coronary artery. 


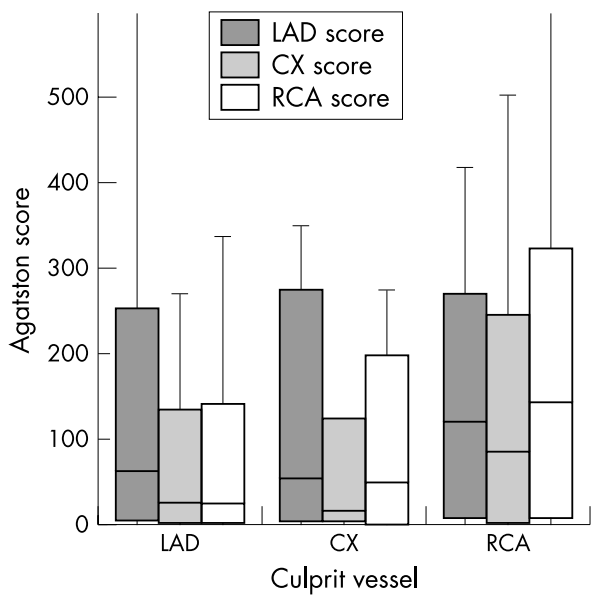

Figure 1 Box plots representing the Agatston score of the left anterior descending coronary artery (LAD), circumflex coronary artery $(C X)$, and right coronary artery (RCA) of patients with myocardial infarction. The patients have been separated according to culprit vessel.

204 non-culprit vessels, 158 were calcified (77.4\%): LAD $68.8 \%$; CX $76.7 \%$; RCA $88.5 \%$. In the control group, coronary calcifications were detected in $59.1 \%$ of the coronary vessels: LAD 50.9\%; CX 39.2\%; RCA 37.2\%. The prevalence of calcifications in the coronary vessels of the control subjects was significantly less than in the infarct patients $(p=0.007$ for comparison with culprit vessels; $\mathrm{p}=0.002$ for comparison with other vessels) (table 2).

In the infarction group, the mean Agatston score of the culprit vessels was 203.5 (254) (LAD 206.9 (291); CX 138.5 (224); RCA 217.9 (266)), while in the non-culprit vessels it was 177.1 (221) (LAD 159.2 (205); CX 191.4 (219); RCA 190.3 (234)). There was no significant difference in the amount of coronary calcification between culprit and non-culprit vessels $(\mathrm{p}=0.4)$. In the controls, the mean Agatston score was 189.2 (413) (LAD 55.7 (136); CX 88.9 (151); RCA 49.3 (111)). The amount of coronary calcium was significantly less in the control group than in the infarct both for the culprit vessels $(p=0.009)$ and for the non-culprit vessels $(p=0.03)$ (fig 1$)$. Figure 2 shows cross sections taken from the heart of a patient following an acute anterior infarction, showing the coronary calcifications.

\section{DISCUSSION}

The amount of coronary calcification detected by electron beam tomography has been identified as a strong predictor of cardiovascular morbidity and mortality..$^{3-9}$ While recently published data have shown an association between the presence and amount of coronary calcifications and the cardiovascular event rate in middle aged and older populations, ${ }^{8}{ }^{14} 22$ similar data for younger patients, though of great interest, ${ }^{6}$ have so far not been published.

In our study, we were able to show that coronary calcifications are present in the vast majority of young patients with a first, unheralded myocardial infarction. Furthermore, the presence and the extent of coronary calcification was significantly greater than in matched controls without a history of symptomatic coronary artery disease. While the overall amount of calcium can be very low in younger patients with myocardial infarction, the age related centile was usually found to be high: $60 \%$ of the patients with acute myocardial infarction had an amount of calcium that was above the 90th centile of age adjusted individuals in a cross sectional population study. ${ }^{21}$ Our results suggest that analysis of coronary calcification by electron beam tomography provides information that augments the predictive value of conventional risk factor analysis. In addition, we found that the presence and extent of calcification in the coronary vessels was independent of the localisation of the myocardial infarction. The culprit vessel was not calcified in all cases, and the mean calcium score of the culprit vessel was only slightly above that of the remaining arteries, as has been shown in earlier histopathological studies. ${ }^{2-4}$ However, the amount of calcification in both culprit and non-culprit vessels was greater than in matched controls. These results add to the findings of previous investigations that have shown a similar extent of calcification in stable coronary plaques and in those prone to rupture. ${ }^{23}$ Necropsy studies have demonstrated that non-calcified plaques are usually associated with the presence of calcified lesions somewhere else in the coronary system. ${ }^{24}$ Schmermund and colleagues reported that the calcified plaque area is strongly correlated with the total plaque area and is significantly greater in patients with sudden cardiac death than in controls. ${ }^{18}$ Thus coronary calcification detected by electron beam tomography is a measure of the total coronary plaque burden, but does not allow differentiation of plaque morphology and stability. ${ }^{23-26}$

Our study was intended to detect and quantify coronary calcification in a younger population with a first unheralded myocardial infarct, and to make comparisons with controls matched for age and risk factors. However, it has some limitations. The controls were selected retrospectively from among individuals who had previously been referred for scanning. These individuals may have been preselected. Second, even though a significant difference in the presence and extent of coronary calcification between patients with and without myocardial infarction could be shown, the sample size was too
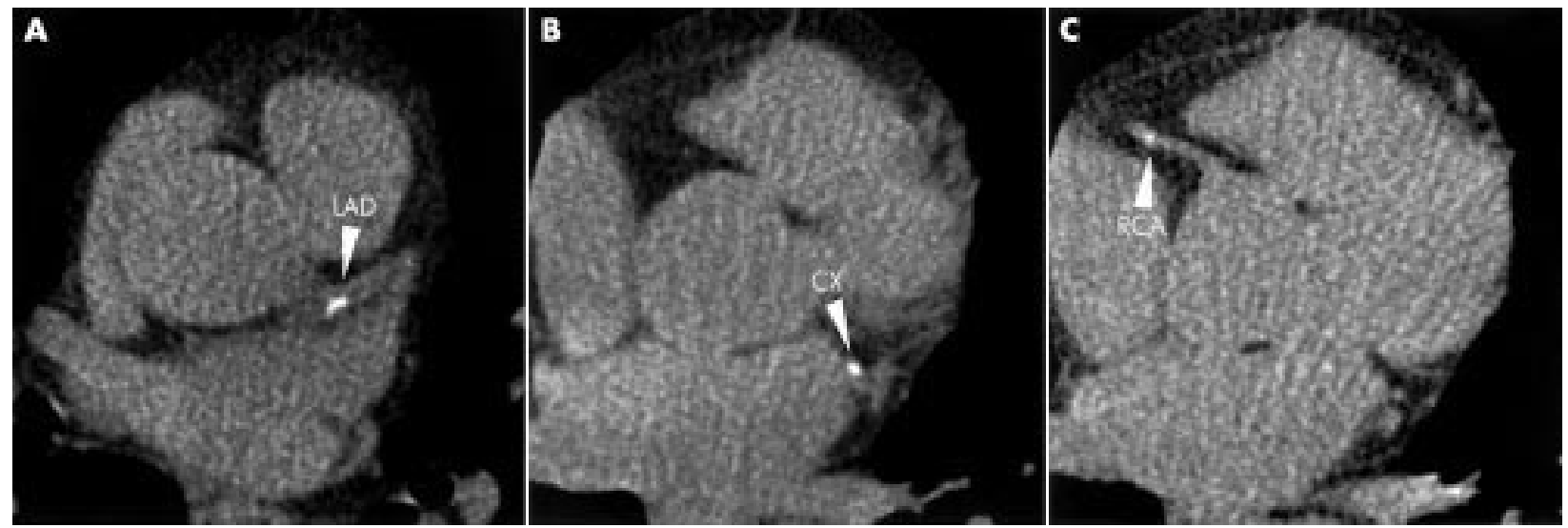

Figure 2 Panels A-C: Cross sections of the heart of a 28 year old male patient after an acute anterior myocardial infarct, showing coronary calcifications (arrowheads) in all coronary vessels (LAD, left anterior descending coronary artery; CX, circumflex artery; RCA, right coronary artery). 
small for a reliable analysis of the effect of other, nontraditional risk factors, which were not included in the matching process but could play a more important role in younger subjects with premature coronary artery disease. Third, and most importantly, we assessed coronary calcifications retrospectively in patients with documented coronary events. Our study design therefore does not rule out the possibility that calcification may have formed as a result of the myocardial infarction. However, this seems very unlikely as the patients were scanned within 14 days of the acute event. Prospective studies will be necessary for a definite assessment of the predictive value of coronary calcification in younger study populations.

In spite of these limitations, our study shows that coronary calcifications can be detected in the vast majority of young patients with their first unheralded myocardial infarction and may therefore be useful for the sensitive detection of patients at increased risk. We were able to show that the presence and extent of coronary calcifications is significantly greater than in controls matched for age, sex, and conventional risk factors. However, the culprit vessel is not necessarily calcified, and the total amount of calcification in young patients at risk may be very small.

\section{Authors' affiliations}

K Pohle, D Ropers, R Mäffert, P Geitner, M Regenfus, M Kusus, W G Daniel, Department of Cardiology, University Erlangen-Nürnberg, Germany

W Moshage, Department of Cardiology, Klinikum Traunstein, Germany S Achenbach, Departments of Radiology and Cardiology, Massachusetts General Hospital, Boston, Massachusetts, USA

\section{REFERENCES}

1 Rumberger JA, Sheedy PF, Breen JF, et al. Electron beam tomography and coronary artery disease: scanning for coronary artery calcification. Mayo Clin Proc 1996;71:369-77.

2 Blankenhorn DH. Coronary artery calcification. Am J Med 1961;31:41-9.

3 McCarthy JH, Palmer FJ. Incidence and significance of coronary artery calcification. Br Heart J 1974;36:499-506.

4 Eggen DA, Strong JP, McGill HC. Coronary calcification: relationship to clinically significant coronary lesions and race, sex and topographic distribution. Circulation 1965:32:948-55.

5 Rumberger JA, Simons DB, Fitzpatrick LA, et al. Coronary artery calcium area by electron beam computed tomography and coronary atherosclerotic plaque area. A histopathologic correlative study. Circulation 1995:92:2157-62.

6 O'Malley PG, Taylor AJ, Jackson JL, et al. Prognostic value of coronary electron beam computed tomography for coronary heart disease events in asymptomatic populations. Am J Cardiol 2000;85:945-8.

7 Arad Y, Spadaro LA, Goodman K, et al. Predictive value of electron beam tomography of the coronary arteries: 19-months follow-up of 1173 asymptomatic subjects. Circulation 1996;93:1951-3.
8 Raggi $\mathbf{P}$, Callister TQ, Cooil B, et al. Identification of patients at increased risk of first unheralded acute myocardial infarction by electron-beam computed tomography. Circulation 2000;101:850-5.

9 Secci A, Wong N, Tang W, et al. Electron beam computed tomographic coronary calcium as a predictor of coronary events. Circulation 1997;96:1 122-9.

10 Detrano RC, Wong ND, Doharty TM, et al. Coronary calcium does not accurately predict near-term future coronary events in high-risk adults. Circulation 1999:99:2633-8.

11 Arad Y, Spadaro LA, Goodman K, et al. Prediction of coronary events with electron beam computed tomography. J Am Coll Cardiol 2000;36: 1253-60

12 He ZX, Hedrick TD, Pratt CM, et al. Severity of coronary artery calcification by electron beam computed tomography predicts silent myocardial ischemia. Circulation 2000;101:244-51.

13 American Heart Association. 2001 Heart and stroke statistical update. Dallas, Texas: American Heart Association, 2000.

14 Mascola A, Ko J, Bakhsheshi $\mathrm{H}$, et al. Electron beam tomography comparison of culprit and non-culprit coronary arteries in patients with acute myocardial infarction. Am J Cardiol 1999;85:1357-9.

15 Schmermund A, Baumgart D, Görge $G$, et al. Coronary artery calcium in acute coronary syndromes: a comparative study of electron-beam computed tomography, coronary angiography, and intracoronary ultrasound in survivors of acute myocardial infarction and unstable angina. Circulation 1997;96:1461-9.

16 Velican C, Velican D. The precursors of coronary atherosclerotic plaques in subjects up to 40 years old. Atherosclerosis 1980;37:33-46.

17 Schmermund A, Schwartz RS, Adamzik M, et al. Coronary atherosclerosis in unheralded sudden coronary death under age 50: histopathologic comparison with "healthy" subjects dying out of hospital. Atherosclerosis 2001:155:499-508.

18 Schmermund A, Baumgart D, Adamzik M, et al. Comparison of electron-beam computed tomography and intracoronary ultrasound in detecting calcified and noncalcified plaques in patients with acute coronary syndromes and no or minimal coronary artery disease. Am J Cardiol 1998;81:141-6.

19 Janowitz W, Agatston A, Kalkan G, et al. Differences in prevalence and extent of coronary artery calcium detected by ultrafast computed tomography in asymptomatic men and women. Am J Cardiol 1993;72:247-54.

20 Agatston AS, Janowitz WR, Hildner FJ, et al. Quantification of coronary artery calcium using ultrafast computed tomography. J Am Coll Cardiol 1990;15:827-32

21 Kaufmann RB, Sheedy PF, Maher JE, et al. Quantity of coronary artery calcium detection by electron beam tomography in asymptomatic subjects and angiographically studied patients. Mayo Clin Proc 1995;70:223-32.

22 Wong ND, Hsu JC, Detrano RC, et al. Coronary calcium evaluation by electron beam computed tomography and its relation to new cardiovascular events. Am J Cardiol 2000;86:495-8.

23 Burke AP, Weber DK, Kolodgie FD, et al. Pathophysiology of calcium deposition in coronary arteries. Herz 2001;26:239-44.

24 Taylor AJ, Burke AP, O'Malley PG, et al. A comparison of the Framingham risk index, coronary artery calcification, and culprit plaque morphology in sudden cardiac death. Circulation 2000;101:1243-8.

25 Sangiorgi G, Rumberger JA, Severson A, et al. Arterial calcification and not lumen stenosis is highly correlated with atherosclerotic plaque burden in humans: a histologic study of 723 coronary artery segments using nondecalcifying methodology. J Am Coll Cardiol 1998;31:126-33.

26 Huang $\mathbf{H}$, Virmani R, Younis $H$, et al. The impact of calcification on the biomechanical stability of atherosclerotic plaques. Circulation 2001;103:1051-6. 